\title{
Participation in social network sites: Associations with the quality of offline and online friendships in German preadolescents and adolescents
}

\author{
Michael Glüer, Arnold Lohaus \\ Department of Psychology, Bielefeld University, Bielefeld, Germany
}

\begin{abstract}
This paper compares offline friendships of preadolescents and adolescents with and without a social network site (SNS) account, and for those who reported having an SNS account, it compares their offline and online friendships. The sample consisted of 1,890 preadolescents and adolescents aged 10 to 18 years, $72.1 \%$ of them with an SNS account. All participants had to describe a good friend whom they meet predominantly offline. The participants with an SNS account additionally had to describe a good SNS friend whom they meet predominantly online. Questionnaires were used to assess perceived friendship quality and the topics primarily discussed with friends. The results showed that participating at an SNS was not connected to friendship quality. However, participants without an SNS account discussed personal problems less often with their offline friends. Participants who reported having an SNS account perceived higher offline compared to online friendship quality. Additionally, female sex, initial offline contact, and frequency of contact had a positive effect on online and offline friendship quality.
\end{abstract}

Keywords: Social network site; social media; friendship quality; preadolescents and adolescents; online and offline friendships

\section{Introduction}

Information and communication technology (ICT), such as social network sites (SNS; i.e. Facebook, Google+ etc.), raise new questions about social norms for communication and social relationship formation in adolescence, in which friendships play a major part in social development. For example, ICT may change the perception of offline friendships in adolescents (Punamäki, Wallenius, Hölttö, Nygård, \& Rimpelä, 2009). Furthermore, the use of ICT enables new ways of friendship formation through online communication (e.g. Valkenburg \& Peter, 2007). As a consequence, the quality, nature and content of friendships may be affected. At present there are only few studies investigating the influence of specific digital media on offline friendships.

Most comparative studies on the quality of offline and online friendship have focused predominantly on the general Internet use (addressing mainly older adolescents). In contrast, the current study focuses on preadolescents and adolescents who are beginning to form online relationships with SNS. SNS are currently the most widespread social media used by German adolescents (MFS, 2014). Little is known so far about the impact of SNS on friendship quality in youth in Germany. Therefore, the aim is to investigate the relation between SNS 
use and general offline friendship quality. Moreover, this study will examine and analyze the possible difference between the offline and online friendship qualities of German preadolescents and adolescents who are part of a social network community. Potential factors influencing the quality of offline and online friendships are also examined in this study.

\section{Development and Impact of Friendships in Childhood and Adolescence}

Friendship is a mutually exclusive social tie between two people. It is primarily defined by positive engagement, intense social activity, positive conflict management, effective task performance, intimacy, and reciprocity (Hartup \& Stevens, 1999; Newcomb \& Bagwell, 1995). Although friendship remains an important process across the lifespan, it changes its function across age (Hartup \& Stevens, 1997). Whereas in childhood friendship is mainly benefit-orientated and is based on shared playtime and activities, mutually shared and intimate social ties do not begin to gain importance until preadolescence (Bigelow \& La Gaipa, 1980; Selman, 1981). This developmental trend reaches its peak in adolescence (Parker, Rubin, Erath, Wojslawowicz, \& Buskirk, 2006), where closeness in terms of security, intimacy, and self-disclosure is the central focus of a friendship (Berndt, 2002; Bukowski, Hoza, \& Boivin, 1994).

\section{Research in Offline and Online Friendship Quality}

Research comparing offline and online friendship quality can be divided into two main areas: (1) the transformation of existing social ties trough ICTs and (2) differences between the quality of online (initially met online) and offline (initially met offline) friendships.

Transformation of social ties. Although several studies exist concerning the transformation of social ties, studies focusing primarily on preadolescents and adolescents are rare. A study by Valkenburg and Peter (2007) that examined the transformation of social ties in adolescence found that $88 \%$ of preadolescents and adolescents used the Internet to maintain their existing offline friendships. Additionally, they assessed the effect of the frequency of online communication (using Instant Messaging or Chat) on the closeness of existing face-toface friendships. Adolescents who communicated more often online felt closer to their friends. These results held for preadolescence (10-11 years) as well as for early and middle adolescence (12-16 years). Supporting these results, Baiocco et al. (2011) found for adolescents (11-16 years) that friendships were closer when personal contact was complemented with electronic communication. Valkenburg and Peter (2009) argued that the positive effect of the Internet on social connectedness might be explained by enhanced self-disclosure using different forms of communication. Online communication makes it easier to talk about topics not easily disclosed, such as feelings and worries. In contrast, the findings of a study by Bryant, Sanders-Jackson and Smallwood (2006), found no evidence that using text messages enhance friendship quality. This indicates that the impact of ICTs on friendship quality may depend on the modality of online communication. Being a member of an SNS may facilitate communication with offline friends and may also make it easier to talk about personal affairs, which may enhance self-disclosure. This can lead to higher offline friendship quality (Baiocco et al., 2011; Valkenburg \& Peter, 2009; Schouten, Valkenburg, \& Peter, 2009). On the other hand, being a member of an SNS may also result in a reduction of offline friendship quality due to the increased time adolescents spent on SNS (Punamäki et al., 2009). So far it is ambiguous if friendships (e.g. quality, frequency of contact or content of conversations) of young people differ in dependency of SNS use.

Differences between the quality of online and offline friendships. Valkenburg, Peter, and Schouten (2006) reported for the Netherlands that 35\% of the surveyed preadolescents and adolescents aged 10-19 years, who were members of a national SNS, established a friendship online. In general, online friendships are rated as less intimate and supportive than offline friendships (Mesch \& Talmud, 2006a, 2006b, 2007). Additionally, offline and online friends differ in their discussed topics and joint activities. Adolescents talk less often about personal problems and romantic relationships and share fewer activities with their online compared to their offline friends (Mesch \& Talmud, 2006b), indicating that offline friendships are closer and more personal. 


\section{Factors Influencing Friendship Quality}

For German youth little is known so far about the frequency, characteristics (e.g. quality) and influencing factors for online friendships in social online networks, although they are the most preferred online media for young people. Internationally, different factors like personality traits (shyness, introversion, anxiety), popularity, loneliness, self-esteem or relationship quality to parents have been identified as potential predictors of friendship quality (e.g. Desjarlais \& Willoughby, 2010; Laghi et al., 2013; McKenna, Green, \& Gleason; Mesch, 2001; Mesch \& Talmud, 2006b). Moreover, several descriptive factors like friendship duration, propinquity (distance to a friend's home), sex, and age play a major role in friendship formation (Mesch \& Talmud, 2006a, 2010). The current study focuses mainly on these descriptive factors.

The duration of a relationship affects the perceived intimacy, closeness, and confidence (Berndt, 2002). Friendships are based on a history of shared experience. Friendship duration was therefore identified as a major predictor for adolescents' offline and online friendship quality in terms of closeness (cf. Hartup \& Stevens, 1999; Mesch \& Talmud, 2010). The distance to a person's home is a key factor for establishing social connections. Children and adolescents typically establish offline friendships to other children from the same area, therefore propinquity is a strong predictor of offline friendship establishment. Mesch and Talmud (2007) found that propinquity also predicts the strength of online ties in adolescents. In contrast, for members of a national SNS in the Netherlands propinquity was not a predictor for online friendship quality (Antheunis, Valkenburg, \& Peter, 2012). Thus, propinquity is an important factor in the context of offline friendships, but the results are mixed for online friendships.

As in offline friendships, most studies support the existence of sex differences in online friendship quality. Mesch and Talmud (2006a, 2006b) found that initial online friendships are closer for female adolescents than for male adolescents. In a study by Valkenburg and Peter (2007) with 10 to 16-years-olds, girls reported closer friendships, although girls and boys did not differ in the frequency of online communication. On the other hand, boys showed better online than offline self-disclosure (Valkenburg, Sumter, \& Peter, 2011). Contrary to the predominant findings, Antheunis et al. (2012) found no sex differences in online and in mixed friendships (online and offline) for members of SNS. Furthermore, in an Italian study girls spent more time on SNS compared to boys, but girls used less often electronic media to maintain friendships (Baiocco et al., 2011; cf. Rideout, Foehr, \& Roberts, 2010).

The results are mixed concerning age as an influencing factor in online or offline friendship quality. In general, older adolescents show more online communication (Lenhart, Madden, \& Hitlin, 2005). Moreover, older adolescents perceive their mixed and online friendships as more rewarding with regard to talking about a wide variety of subjects and self-disclosing intimate information (Mesch \& Talmud, 2006b; Valkenburg \& Peter, 2007). However, Mesch and Talmud (2006a, 2006b) found that age was not a predictor of the strength of ties for adolescents.

\section{The Current Study}

The current study compares offline friendships of preadolescents and adolescents with and without an SNS account, and for those who reported having an SNS account, it compares their offline and online friendships. There are several reasons to focus on a specific kind of social media. First of all, different social media have different significance for adolescents. Secondly, $96 \%$ of the German preadolescents and adolescents aged 12 to 19 years are members of an SNS (MFS, 2014), which underlines the specific significance of SNS for adolescents. Thirdly, SNS play a major part in maintaining existing friendships and establishing new ones. They provide manifold ways of online communication, which are fundamental for friendship development (like contact lists, possibilities to initiate new contacts, providing profiles and opportunities for chats etc.) and may therefore especially facilitate peer interactions (Williams \& Merten, 2008). In this study, we investigate three research questions concerning offline and online friendship quality in young preadolescents and adolescents aged 10 to 18 with and without SNS-account in Germany:

1. Do preadolescents' and adolescents' participating versus not participating in SNSs differ regarding their offline friendship quality? As Valkenburg and Peter (2007) showed, offline friendships, which are additionally maintained 
online, show higher friendship quality than friendships maintained exclusively offline. Additionally, the frequency of interaction with a friend was associated with higher friendship quality. It is therefore expected that offline friendships are evaluated more positively if preadolescents and adolescents have broader chances to communicate with each other, not only offline, but also online (Hypothesis 1). This is the case especially if they are participating in an SNS because this provides the chance to meet both offline and online. Additionally, we analyze potential differences in friendship quality of adolescents participating versus not participating in SNSs by comparing the discussed topics. We expect that differences in friendship quality are also shown by differences in shared personal topics.

2. Do adolescents participating in an SNS show differences in the friendship quality between offline and online friends? The second research question focuses on adolescents participating in an SNS. Friends are compared by whether they are contacted predominately offline versus online in SNSs. The expectation (Hypothesis 2 ) is that the friendship quality is increased for predominately offline relationships (which include the possibility of meeting online). Friendships with increased offline contact have more possibilities to gain trust and intimacy, which may be due to the increased occurrence of social cues. Especially in preadolescence and adolescence, where selfdisclosure is a main characteristic of friendships, higher occurrences of social cues increase the chances for personal exchange. Therefore, we expect offline friendships to share more personal information than online SNS friendships.

3. Which factors affect offline and online friendships of adolescents using SNSs? The third research question is related to factors affecting friendship quality. The focus is on initial contact, propinquity, frequency of contact, age, and sex. We expect from previous findings that initial contact, propinquity, and frequency of contact have a positive impact on offline and online friendship quality (Hypothesis 3). Additionally, we expect that females show higher friendship quality than do males. There are no clear expectations for age because previous research showed inconsistent results for this factor.

\section{Method}

\section{Participants}

The study included 1,890 preadolescents and adolescents (49.1\% females and $50.9 \%$ males) in grades 5 to 10 from 26 German secondary schools. Schools were initially recruited using telephone lists of schools in the region Northrine-Westfalia (Germany). Stratified sampling technique was used to obtain children and adolescent from different school types and age. Eight schools were invited to participate from two larger cities (between 100,000400,000 inhabitants), seven schools from medium-sized towns (between 50,000-99,000 inhabitants) and 11 schools from smaller towns (between 20,000-49,999 inhabitants). The included schools covered the whole range of performance levels in Germany. In German secondary schools, $10.1 \%$ of the students have a migration background (Statistisches Bundesamt, 2013). This information, however, was not recorded in this study.

Data analysis focuses on the comparison between offline friendship quality of participants with and without SNS experiences. In addition, for participants with SNS experience their offline and and online friendship quality is compared. Therefore, three different groups were used for different parts of the data analysis: Participants with SNS $(72.1 \%)$ and without SNS $(27.9 \%)$ to be able to compare their offline friendships and - within the group of participants with SNS - those who reported having offline and online friends ( $41.2 \%$ of the SNS group) to be able to compare their online and offline friendships. For the data analyses the grades 5 and 6 (Mean age 11.25 years; $S D=0.4$ ), 7 and 8 (Mean age 13.52 years, $S D=0.3$ ), and 9 and 10 were combined (Mean Age 15.67 years, $S D=0.4$ ). Table 1 contains descriptive statistics for the participants' groups. The differences in reported sample sizes in analyses are due to missing values in specific measures.

Participation in the study required parents' permission. The recruitment of the samples and the study's procedure were in accordance with the ethical guidelines of the American Psychological Association (APA) and the Society for Research in Child Development (SRCD). The conductance of the study was approved by an independent ethical review board. 
Table 1. Descriptive Statistics of the Investigated Participant Groups.

\begin{tabular}{|c|c|c|c|c|c|c|}
\hline & \multicolumn{2}{|c|}{$\begin{array}{l}\text { Without SNS } \\
\text { account } \\
(N=528)\end{array}$} & \multicolumn{2}{|c|}{$\begin{array}{l}\text { With SNS account } \\
\quad(N=1362)\end{array}$} & \multicolumn{2}{|c|}{$\begin{array}{l}\text { Participants with SNS } \\
\text { account and offline as } \\
\text { well as online friends } \\
\qquad(N=561)\end{array}$} \\
\hline & $N$ & Mean & $N$ & Mean & $N$ & Mean \\
\hline Sex (Girls) & 294 & $55.68 \%$ & 635 & $46.6 \%$ & 260 & $46.4 \%$ \\
\hline Grade & \multicolumn{2}{|c|}{$(N=526)$} & \multicolumn{2}{|c|}{$(N=1362)$} & \multicolumn{2}{|c|}{$(N=508)$} \\
\hline 5-7 (11 years) & 281 & $53.4 \%$ & 265 & $19.5 \%$ & 112 & $18.3 \%$ \\
\hline 7-8 (14 years) & 204 & $38.8 \%$ & 672 & $49.3 \%$ & 295 & $52.4 \%$ \\
\hline 9-10 (16 years) & 41 & $7.8 \%$ & 425 & $31.2 \%$ & 154 & $29.3 \%$ \\
\hline Sex by Grade (Girls) & \multicolumn{2}{|c|}{$(N=526)$} & \multicolumn{2}{|c|}{$(N=1362)$} & \multicolumn{2}{|c|}{$(N=508)$} \\
\hline 5-7 (11 years) & 134 & $47.7 \%$ & 101 & $38.1 \%$ & 39 & $34.8 \%$ \\
\hline 7-8 (14 years) & 136 & $66.7 \%$ & 334 & $49.7 \%$ & 145 & $49.1 \%$ \\
\hline 9-10 (16 years) & 23 & $56.1 \%$ & 200 & $47.1 \%$ & 76 & $49.3 \%$ \\
\hline
\end{tabular}

\section{Procedure}

The data collection took place in computer rooms at the schools. All questionnaires were presented computerbased using the EFS Survey software (version 10.1). The assessments started with a verbal introduction of the online questionnaire and the meaning of an SNS.

Students participating in online social networks were asked to fill out the friendship questions for a good offline friend whom they meet predominantly offline. Additionally, they were asked if they have a good online SNS friend. If they agreed, they were additionally asked to fill out the friendship questions for the online friend whom they meet predominantly online on an SNS. As research shows most nowadays friendships are related to offline and online contexts (Antheunis et al., 2012; Gross, 2004; Reich, Subrahmanyam, \& Espinoza, 2012; Valkenburg \& Peter, 2007). Therefore, we defined in our study online friendships as ties that are mainly maintained online and offline friendships as ties that are mainly maintained offline. To make sure that all participants referred to the same concept of friendship the participants received an explanation of a good friend: "A good friend is somebody you really like to be together. You can tell him/her secrets and have fun with him/her".

To ensure that ratings of predominantly offline and predominantly online SNS friends were related to different friends, the first names of the friends were checked to control for double nominations. Three percent of the participants nominated the same friend as both their offline and online friend, and were therefore excluded from subsequent analyses. Students without online network experiences were provided with the friendship questions only for an offline friend. Responding to the friendship questions typically took 15 to 20 minutes.

\section{Measures}

Description of friend. Offline and and online friends' descriptions involved questions about their sex, age, and where they initially met ( $1=$ online or $2=$ offline). Means and SDs for offline and online friends are presented in Table 2.

Offline and online friendship quality. To assess the respondents' friendship quality perceptions the McGill Friendship Questionnaire - Respondent's Affection (MFQ-RA) was used (Mendelson \& Aboud, 1999, 2012). The MFQ-RA is a 15 item context-independent questionnaire to assess feelings and satisfaction with a specific friend (e.g., "I am happy with my friendship with ..."). Friendship quality is rated by a nine-point rating scale ranging from (1) very much disagree to (9) very much agree. A German version of the revised McGill Friendship Questionnaire was constructed by translation (English to German) and back translation of two independent translators (in accordance with Behling \& Law, 2000). The German version was based on 14 items because it was difficult to find an adequate German translation for one item. 
As in the original questionnaire, a principal components analysis indicated a one-dimensional structure (taking $\lambda$ $>1$ as the critical value) with eigenvalues of $\lambda_{1}=10.75, \lambda_{2}=.68, \lambda_{3}=.52, \lambda_{4}=.36, \lambda_{5}=.31$. The first factor accounts for $76.8 \%$ of the variance. This factor analysis was based on the description of an offline friend that was available for the total sample. The internal consistency of this scale was $a=.97$ (offline friendship quality). For online friendship quality (participants with an SNS account) the internal consistency of the scale was $a=.98$. Consequently, sum scores across all 14 items were used in this study to indicate the perceived friendship quality. Means and SDs are presented in Table 3 for offline friendship quality of participants with and without an SNS account and in Table 4 for offline and online friendship quality of participants with an SNS account.

Friendship topics of conversation. The participants were additionally asked about topics they had talked about with their friend during the last few months. The following topics were provided: (a) school (e.g., teachers, grades, peers), (b) school-related contents (e.g., homework, mathematical solutions), (c) Internet (e.g., great websites, funny YouTube videos), (d) parents or siblings, (e) hobbies, ( $f$ ) personal problems and secrets, and (g) girls or boys whom you like. A five-point response scale was used, ranging from (1) never to (5) very often. The topics were adapted based on Mesch and Talmund (2006a). The items are analyzed separately below, and thus no total score was calculated (s. Table 3 and 4 for Means and SDs).

Distance of friend's home: Friends home town distance was assessed by a 5-point rating scale ranging from (1) in the neighborhood, (2) in the same town, (3) in another town less than 100 kilometers away, (4) in another town more than 100 kilometers away, to (5) in another country. Means and SDs are presented in Table 2.

Frequency of contact. Frequency of contact was measured by a 6-point rating scale ranging from (1) less than once a week, (2) once or twice a week, (3) three or four times a week, (4) five or six times a week (5) daily, to (6) several times daily (s. Table 2 for Means and SDs).

Overall friendship Quality (Strength of tie). Participants had to indicate the strength of their friendship ties by a 10-point scale ranging from (1) very strong friendship to (10) very weak friendship (s. Table 3 and 4 for Means and SDs).

Duration of friendship. To measure friendship duration participants indicated how long they had been friends (in years; s. Table 3 and 4 for Means and SDs).

In the case of preadolescents and adolescents with a social network account, all items had additionally to be assessed for a good online friend.

\section{Data Analysis}

The main statistical analyses are related to analysis of variance. In the case of sets of dependent variables, multivariate analyses of variance are calculated. Analyses of variance with repeated measures were calculated for comparisons between offline and online friendship indicators. Regression analysis was used to determine factors associated with offline and online friendship quality. In all analyses, sex and grade were included as covariates. Because of the large sample size, alpha was generally set to $p<.01$ as critical value for the statistical analyses.

\section{Results}

\section{Preliminary Analyses}

Table 2 shows descriptive values for the offline friendships by social network site status. There are only marginal differences between the descriptions of offline friends of participants with and without an SNS account. Members of SNS reported that their friends were slightly older compared to non-members. The comparison between the offline and online friendships of participants with an SNS account reveals differences for the initial contact and friends home distance. The initial contact of online friend was more often online, and the online friend lived more far away compared to the offline friends. 
Table 2. Means and Standard Deviations (in parentheses) for offline and online Friendships by Social Network Status.

\begin{tabular}{|c|c|c|c|c|}
\hline & \multirow{2}{*}{$\begin{array}{l}\text { Without SNS- } \\
\text { account } \\
(N=528) \\
\text { Offline } \\
\text { Friends } \\
\end{array}$} & \multirow{2}{*}{$\begin{array}{c}\text { With SNS- } \\
\text { account } \\
(N=1362) \\
\text { Offline Friends }\end{array}$} & \multicolumn{2}{|c|}{$\begin{array}{l}\text { Participants with SNS-account } \\
\text { and offline as well as online } \\
\text { friends } \\
(N=561)\end{array}$} \\
\hline & & & Online Friends & Offline Friends \\
\hline Sex (Girls) & $55.7 \%$ & $48.3 \%$ & $55.7 \%$ & $48.8 \%$ \\
\hline Age & $12.35(2.07)$ & $14.38(4.23)$ & $14.41(4.76)$ & $14.90(4.50)$ \\
\hline Initial Contact & $(N=521)$ & $(N=1325)$ & $(N=490)$ & $(N=508)$ \\
\hline Offline & $97.9 \%$ & $94.6 \%$ & $57.8 \%$ & $94.6 \%$ \\
\hline Online & $2.2 \%$ & $5.5 \%$ & $42.2 \%$ & $5.5 \%$ \\
\hline Distance & $(N=521)$ & $(N=1325)$ & $(N=490)$ & $(N=508)$ \\
\hline Same neighborhood & $25.3 \%$ & $26 \%$ & $12.9 \%$ & $24.4 \%$ \\
\hline Same Town & $52.2 \%$ & $58 \%$ & $33.9 \%$ & $58.1 \%$ \\
\hline Not more than $100 \mathrm{~km}$ & $18.8 \%$ & $12.5 \%$ & $21.6 \%$ & $12.6 \%$ \\
\hline More than $100 \mathrm{~km}$ & $3.1 \%$ & $2.4 \%$ & $21.6 \%$ & $3.5 \%$ \\
\hline Another Country & $0.6 \%$ & $1.2 \%$ & $10.0 \%$ & $1.4 \%$ \\
\hline Contact frequency & $(N=521)$ & $(N=1325)$ & $(N=490)$ & $(N=508)$ \\
\hline Less than once a week & $6.5 \%$ & $3.3 \%$ & $3.5 \%$ & $17.6 \%$ \\
\hline Once or twice a week & $13.6 \%$ & $9.1 \%$ & $11.0 \%$ & $17.6 \%$ \\
\hline $\begin{array}{l}\text { Three or four times a } \\
\text { week }\end{array}$ & $12.3 \%$ & $13.5 \%$ & $12.4 \%$ & $16.5 \%$ \\
\hline Five or six times a week & $23.8 \%$ & $20.3 \%$ & $26.4 \%$ & $12.7 \%$ \\
\hline Daily & $25.0 \%$ & $25.3 \%$ & $26.4 \%$ & $17.1 \%$ \\
\hline Several times daily & $18.8 \%$ & $28.5 \%$ & $30.3 \%$ & $18.6 \%$ \\
\hline
\end{tabular}

\section{Comparison of Offline Friendship Quality between Participants with and Without a SNS (Hypothesis 1)}

Friendship quality. To address possible differences between offline friendships of participants with and without SNS account, an analysis of variance was calculated with the online network status (online versus offline) as independent variable and the perceived quality of friendship as the dependent variable. Sex and grade were included as covariates in this analysis. The results did not indicate a significant mean difference for the online network status $\left(F_{(1,1834)}=1.89, p>.01, \eta^{2}<.01\right)$. Regarding the covariates, the analysis showed a significant effect for $\operatorname{sex}\left(F_{(1,1834)}=163.64, p<.001, \eta^{2}=.08\right)$, but not for grade (Table 3). As an inspection of the means showed, girls reported higher friendship qualities than did boys.

Discussed topics. A multivariate analysis of variance was calculated to address differences regarding the topics discussed by participants with and without SNS accounts. The seven topic items were included as dependent variables, whereas the online network status was the independent variable. Sex and grade were again included as covariates. The results indicated a multivariate effect of the online network status $\left(F_{(7,1807)}=11.52, p<.001, \eta^{2}\right.$ $=.04)$. The univariate analyses demonstrated significant differences for talking about Internet-related contents $\left(F_{(1,1813)}=25.35, p<.001, \eta^{2}=.04\right)$, for talking about personal problems and secrets $\left(F_{(1,1813)}=19.57, p<.001, \eta^{2}=\right.$ $.01)$, and for talking about girls or boys whom you like $\left(F_{(1,1812)}=29.75, p<.001, \eta^{2}=.02\right)$. In all cases, the mean values were increased for preadolescents and adolescents participating in an SNS (Table 3). Additionally, there were multivariate sex effects $\left(F_{(7,1806)}=65.92, p<.001, \eta^{2}=.20\right)$ and grade effects $\left(F_{(7,1806)}=5.92, p<.001, \eta^{2}=\right.$ 
.02). In the case of sex, the values were significantly increased for girls in comparison to boys (Table 3). The only exception was found for talking about the Internet (e.g., great websites, funny YouTube videos), which demonstrated a difference in favor of boys. Regarding grades, there was only a significant difference with regard to talking about school-related content (e.g., homework) at the univariate level, with increasing values across grades.

Table 3. Means and Standard Deviations (in parentheses) for Variables Indicating the Friendship Quality of offline friends by Social Network Status, Sex, and Grade.

\begin{tabular}{|c|c|c|c|c|c|c|c|}
\hline Variable & $\begin{array}{c}\text { Social } \\
\text { network } \\
\text { account }\end{array}$ & $\begin{array}{c}\text { No } \\
\text { account }\end{array}$ & Girls & Boys & $\begin{array}{c}\text { Grades } \\
5 / 6\end{array}$ & $\begin{array}{c}\text { Grades } \\
7 / 8\end{array}$ & $\begin{array}{c}\text { Grades } \\
9 / 10\end{array}$ \\
\hline $\begin{array}{l}\text { Friendship } \\
\text { quality score }\end{array}$ & $\begin{array}{l}108.30 \\
(24.10)\end{array}$ & $\begin{array}{l}112.35 \\
(18.81)\end{array}$ & $\begin{array}{l}116.40 \\
(15.66)\end{array}$ & $\begin{array}{l}103.65 \\
(25.26)\end{array}$ & $\begin{array}{l}111.20 \\
(21.89)\end{array}$ & $\begin{array}{l}109.77 \\
(21.52)\end{array}$ & $\begin{array}{l}109.04 \\
(22.88)\end{array}$ \\
\hline $\begin{array}{l}\text { School (e.g., } \\
\text { teachers) }\end{array}$ & $\begin{array}{c}3.31 \\
(1.27)\end{array}$ & $\begin{array}{c}3.37 \\
(1.30)\end{array}$ & $\begin{array}{c}3.55 \\
(1.21)\end{array}$ & $\begin{array}{c}3.10 \\
(1.31)\end{array}$ & $\begin{array}{c}3.16 \\
(1.35)\end{array}$ & $\begin{array}{c}3.32 \\
(1.29)\end{array}$ & $\begin{array}{c}3.51 \\
(1.17)\end{array}$ \\
\hline $\begin{array}{l}\text { School-related } \\
\text { topics }\end{array}$ & $\begin{array}{c}2.83 \\
(1.34)\end{array}$ & $\begin{array}{c}2.96 \\
(1.34)\end{array}$ & $\begin{array}{c}2.98 \\
(1.33)\end{array}$ & $\begin{array}{c}2.76 \\
(1.33)\end{array}$ & $\begin{array}{c}2.90 \\
(1.36)\end{array}$ & $\begin{array}{c}2.83 \\
(1.35)\end{array}$ & $\begin{array}{c}2.91 \\
(1.28)\end{array}$ \\
\hline $\begin{array}{l}\text { Internet (e.g., } \\
\text { websites) }\end{array}$ & $\begin{array}{l}3.14 \\
(1.31)\end{array}$ & $\begin{array}{c}2.70 \\
(1.41)\end{array}$ & $\begin{array}{c}2.82 \\
(1.34)\end{array}$ & $\begin{array}{c}3.22 \\
(1.34)\end{array}$ & $\begin{array}{c}2.92 \\
(1.42)\end{array}$ & $\begin{array}{l}3.06 \\
(1.36)\end{array}$ & $\begin{array}{c}3.05 \\
(1.27)\end{array}$ \\
\hline $\begin{array}{l}\text { Parents or } \\
\text { siblings }\end{array}$ & $\begin{array}{c}3.06 \\
(1.31)\end{array}$ & $\begin{array}{c}2.95 \\
(1.34)\end{array}$ & $\begin{array}{c}3.37 \\
(1.22)\end{array}$ & $\begin{array}{c}2.70 \\
(1.33)\end{array}$ & $\begin{array}{c}2.87 \\
(1.38)\end{array}$ & $\begin{array}{c}3.05 \\
(1.31)\end{array}$ & $\begin{array}{c}3.18 \\
(1.25)\end{array}$ \\
\hline Hobbies & $\begin{array}{c}3.34 \\
(1.28)\end{array}$ & $\begin{array}{c}3.34 \\
(1.32)\end{array}$ & $\begin{array}{l}3.45 \\
(1.20)\end{array}$ & $\begin{array}{c}3.45 \\
(1.20)\end{array}$ & $\begin{array}{c}3.22 \\
(1.37)\end{array}$ & $\begin{array}{c}3.33 \\
(1.30)\end{array}$ & $\begin{array}{c}3.40 \\
(1.18)\end{array}$ \\
\hline $\begin{array}{l}\text { Personal } \\
\text { problems }\end{array}$ & $\begin{array}{l}3.45 \\
(1.41)\end{array}$ & $\begin{array}{l}3.13 \\
(1.46)\end{array}$ & $\begin{array}{l}3.85 \\
(1.26)\end{array}$ & $\begin{array}{c}2.88 \\
(1.43)\end{array}$ & $\begin{array}{c}3.21 \\
(1.49)\end{array}$ & $\begin{array}{c}3.37 \\
(1.42)\end{array}$ & $\begin{array}{l}3.53 \\
(1.36)\end{array}$ \\
\hline $\begin{array}{l}\text { Girls or boys } \\
\text { you like }\end{array}$ & $\begin{array}{c}3.36 \\
(1.49)\end{array}$ & $\begin{array}{l}2.85 \\
(1.55)\end{array}$ & $\begin{array}{c}3.55 \\
(1.46)\end{array}$ & $\begin{array}{c}2.88 \\
(1.51)\end{array}$ & $\begin{array}{c}2.93 \\
(1.58)\end{array}$ & $\begin{array}{l}3.28 \\
(1.50)\end{array}$ & $\begin{array}{c}3.38 \\
(1.47)\end{array}$ \\
\hline Overall quality $^{1}$ & $\begin{array}{c}1.84 \\
(1.40)\end{array}$ & $\begin{array}{c}1.86 \\
(1.36)\end{array}$ & $\begin{array}{c}1.67 \\
(1.21)\end{array}$ & $\begin{array}{c}2.02 \\
(1.51)\end{array}$ & $\begin{array}{l}1.72 \\
(1.34)\end{array}$ & $\begin{array}{c}1.87 \\
(1.41)\end{array}$ & $\begin{array}{c}1.92 \\
(1.34)\end{array}$ \\
\hline $\begin{array}{l}\text { Friendship } \\
\text { duration }\end{array}$ & $\begin{array}{c}5.46 \\
(6.53)\end{array}$ & $\begin{array}{c}5.11 \\
(5.44)\end{array}$ & $\begin{array}{c}5.51 \\
(7.05)\end{array}$ & $\begin{array}{c}5.17 \\
(4.49) \\
\end{array}$ & $\begin{array}{c}4.76 \\
(5.50)\end{array}$ & $\begin{array}{c}5.27 \\
(6.05)\end{array}$ & $\begin{array}{r}6.06 \\
(5.94)\end{array}$ \\
\hline
\end{tabular}

Note: $1=$ Small numbers indicate higher overall quality (scale: $1=$ very strong friendship, $10=$ very weak friendship)

Overall quality. The preadolescents and adolescents were also asked to evaluate the overall quality of their friendship (ranging from very strong to very weak friendship). A univariate analysis of variance indicated no difference between adolescents not participating versus participating in an SNS $\left(F_{(1,1841)}=2.92, p>.05, \eta^{2}<.01\right.$; Table 3). Both covariates (sex and grade) showed significant influences on this variable $\left(F_{(1,1841)}=29.61, p<.001\right.$, $\eta^{2}=.02$ for sex and $F_{(1,1841)}=2.92, p<.01, \eta^{2}=.01$ for grade). In general, girls evaluated their friendships as stronger than did boys, and students in lower grades evaluated their friendships as stronger than did those in higher grades (s. Table 3; please note that lower numbers represent an increased quality assessment).

Friendship duration. An additional univariate analysis of variance focused on the length of the friendship (in years), which may also indicate friendship quality. Again, there was no difference with regard to the social network status (online versus offline; $\left.F_{(1,1841)}<.01, p>.05, \eta^{2}<.01\right)$. There was no influence of sex as a covariate, 
but a grade influence $\left(F_{(1,1841)}=9.84, p<.01, \eta^{2}=.01\right)$. As can be expected, the duration of the friendship was longer with increasing grades (s. Table 3).

\section{Comparison of SNS-Participants Regarding their Offline and Online Friendship Quality (Hypotheses 2 and 3)}

The following sections are related to the comparison between offline and online SNS friendships within the sample of participants with an SNS account (addressing Hypothesis 2) and to possible factors that may be associated with the offline and online friendship quality (addressing Hypothesis 3). The basis of the analyses is the description of a good friend whom the participants meet predominately offline and a good friend whom they predominately meet online in an SNS.

Friendship quality. An analysis of variance with repeated measures was calculated for the perceived friendship quality score (with sex and grade as covariates). The results showed a significant difference between both friendship descriptions $\left(F_{(1,489)}=10.56, p<.01, \eta^{2}=.02\right)$. The means indicated a lower friendship quality for the online descriptions (s. Table 4). There were no additional influences of sex and grade. Table 4 also shows the descriptions of online and offline friends for both sexes separately because there were influences of sex in some of the analyses reported below.

Table 4. Means and Standard Deviations (in parentheses) for the Description of Offline Versus Online Friends (Total Sample and Both Sexes Separately).

\begin{tabular}{|c|c|c|c|c|c|c|}
\hline Variable & $\begin{array}{l}\text { Offline } \\
\text { friend } \\
\text { (total) }\end{array}$ & $\begin{array}{l}\text { Online } \\
\text { friend } \\
\text { (total) }\end{array}$ & $\begin{array}{l}\text { Offline } \\
\text { friend } \\
\text { (girls) }\end{array}$ & $\begin{array}{l}\text { Online } \\
\text { friend } \\
\text { (girls) }\end{array}$ & $\begin{array}{l}\text { Offline } \\
\text { friend } \\
\text { (boys) }\end{array}$ & $\begin{array}{l}\text { Online } \\
\text { friend } \\
\text { (boys) }\end{array}$ \\
\hline $\begin{array}{l}\text { Friendship } \\
\text { quality score }\end{array}$ & $\begin{array}{l}108.11 \\
(24.44)\end{array}$ & $\begin{array}{c}95.89 \\
(29.54)\end{array}$ & $\begin{array}{l}116.06 \\
(16.48)\end{array}$ & $\begin{array}{c}99.35 \\
(26.81)\end{array}$ & $\begin{array}{l}102.78 \\
(26.11)\end{array}$ & $\begin{array}{c}92.65 \\
(32.07)\end{array}$ \\
\hline $\begin{array}{l}\text { School (e.g., } \\
\text { teachers) }\end{array}$ & $\begin{array}{l}3.28 \\
(1.33)\end{array}$ & $\begin{array}{c}2.70 \\
(1.43)\end{array}$ & $\begin{array}{c}3.50 \\
(1.122)\end{array}$ & $\begin{array}{c}2.77 \\
(1.44)\end{array}$ & $\begin{array}{c}3.14 \\
(1.30)\end{array}$ & $\begin{array}{c}2.65 \\
(1.44)\end{array}$ \\
\hline $\begin{array}{l}\text { School-related } \\
\text { topics }\end{array}$ & $\begin{array}{c}2.79 \\
(1.37)\end{array}$ & $\begin{array}{c}2.41 \\
(1.43)\end{array}$ & $\begin{array}{c}2.91 \\
(1.34)\end{array}$ & $\begin{array}{c}2.43 \\
(1.42)\end{array}$ & $\begin{array}{c}2.75 \\
(1.33)\end{array}$ & $\begin{array}{c}2.42 \\
(1.45)\end{array}$ \\
\hline $\begin{array}{l}\text { Internet (e.g., } \\
\text { websites) }\end{array}$ & $\begin{array}{l}3.25 \\
(1.34)\end{array}$ & $\begin{array}{c}2.91 \\
(1.46)\end{array}$ & $\begin{array}{l}2.99 \\
(1.31)\end{array}$ & $\begin{array}{c}2.84 \\
(1.44)\end{array}$ & $\begin{array}{l}3.28 \\
(1.30)\end{array}$ & $\begin{array}{c}2.98 \\
(1.48)\end{array}$ \\
\hline $\begin{array}{l}\text { Parents or } \\
\text { siblings }\end{array}$ & $\begin{array}{l}3.08 \\
(1.38)\end{array}$ & $\begin{array}{c}2.77 \\
(1.41)\end{array}$ & $\begin{array}{c}3.44 \\
(1.20)\end{array}$ & $\begin{array}{c}3.03 \\
(1.32)\end{array}$ & $\begin{array}{c}2.73 \\
(1.31)\end{array}$ & $\begin{array}{c}2.56 \\
(1.48)\end{array}$ \\
\hline Hobbies & $\begin{array}{c}3.32 \\
(1.32)\end{array}$ & $\begin{array}{c}3.09 \\
(1.41)\end{array}$ & $\begin{array}{c}3.43 \\
(1.19)\end{array}$ & $\begin{array}{c}3.15 \\
(1.38)\end{array}$ & $\begin{array}{c}3.25 \\
(1.136)\end{array}$ & $\begin{array}{c}3.05 \\
(1.45)\end{array}$ \\
\hline $\begin{array}{l}\text { Personal } \\
\text { problems }\end{array}$ & $\begin{array}{l}3.52 \\
(1.44)\end{array}$ & $\begin{array}{l}3.08 \\
(1.48)\end{array}$ & $\begin{array}{c}3.99 \\
(1.20)\end{array}$ & $\begin{array}{c}3.32 \\
(1.43)\end{array}$ & $\begin{array}{l}2.97 \\
(1.41)\end{array}$ & $\begin{array}{c}2.88 \\
(1.50)\end{array}$ \\
\hline $\begin{array}{l}\text { Girls or boys } \\
\text { you like }\end{array}$ & $\begin{array}{l}3.41 \\
(1.54)\end{array}$ & $\begin{array}{c}3.00 \\
(1.54)\end{array}$ & $\begin{array}{c}3.73 \\
(1.40)\end{array}$ & $\begin{array}{c}3.14 \\
(1.52)\end{array}$ & $\begin{array}{c}3.02 \\
(1.49)\end{array}$ & $\begin{array}{c}2.88 \\
(1.55)\end{array}$ \\
\hline Overall quality $^{1}$ & $\begin{array}{c}1.93 \\
(1.60)\end{array}$ & $\begin{array}{c}3.12 \\
(2.24)\end{array}$ & $\begin{array}{c}1.66 \\
(1.20)\end{array}$ & $\begin{array}{c}3.35 \\
(2.35)\end{array}$ & $\begin{array}{c}2.01 \\
(1.53)\end{array}$ & $\begin{array}{c}2.90 \\
(2.15)\end{array}$ \\
\hline $\begin{array}{l}\text { Friendship } \\
\text { duration }\end{array}$ & $\begin{array}{c}5.27 \\
(6.83)\end{array}$ & $\begin{array}{c}5.05 \\
(10.56)\end{array}$ & $\begin{array}{c}5.52 \\
(7.22)\end{array}$ & $\begin{array}{c}4.01 \\
(4.74)\end{array}$ & $\begin{array}{c}5.32 \\
(4.81)\end{array}$ & $\begin{array}{c}5.99 \\
(13.66)\end{array}$ \\
\hline
\end{tabular}

Note: $1=$ Small numbers indicate higher overall quality (scale: 1 = very strong friendship, $10=$ very weak friendship) 
Discussed topics. Regarding the topics discussed with predominantly offline and online SNS friends, the withinsubjects analysis of variance demonstrated only a significant difference for talking about personal problems and secrets $\left(F_{(1,481)}=16.61, p<.001, \eta^{2}=.03\right)$. As the means showed, personal problems were more often discussed with offline than online friends. There was an additional significant interaction with sex, indicating that this effect is larger for girls than boys $\left(F_{(1,481)}=15.43, p<.001, \eta^{2}=.03\right)$. There was no additional influence of grade.

Overall quality. Moreover, a within-subjects analysis of variance indicated a significant difference for the overall quality (strength of tie) of the described offline versus online friendship $\left(F_{(1,495)}=12.37, p<.01, \eta^{2}=.02\right)$. The perceived quality was significantly higher for offline than online friendships. As the analysis of variance showed, there was an additional influence of $\operatorname{sex}\left(F_{(1,495)}=10.79, p<.01, \eta^{2}=.02\right)$, indicating that the difference between offline and online friendships is larger for girls than boys. There was no significant influence of grade.

Influences on offline versus online friendship quality (Hypothesis $\mathbf{3}$ ). The previous sections showed that online friendships might differ from offline friendships. The forthcoming sections focus on possible factors that may be associated with the offline and online friendship quality. The following factors were included as predictor variables in the regression analysis: (a) initial contact (online versus offline), (b) distance of the friend's home (ranging from in the neighborhood to in another country), and (c) frequency of contact (ranging from less than once a week to several times a day). The quality of friendship score was used as a criterion. Two separate hierarchical regression analyses were calculated for the online and offline quality of friendship indicators as criterion variables. Sex and grade were included as control variables in the first step. The results (s. Table 5) are very similar for offline and online friendships: Sex was a significant predictor, with an increased friendship quality reported by females. Moreover, the kind of initial contact and the frequency of contact were significant predictors. In particular, an initial offline contact and a high contact frequency were associated with an increased friendship quality (both in the descriptions of an offline and an online friend). The results were similar if the ratings of the overall friendship quality were used as criterion variable (instead of the friendship quality scores).

Table 5. Prediction of the Offline and Online Friendship Quality by Sex and Grade (Control Variables) and the Kind of Initial Contact (Online Versus Offline), the Distance of the Friend's Home, and the Frequency of Contact (Results of Hierarchical Regression Analyses).

\begin{tabular}{|c|c|c|c|}
\hline Variable in regression & B & $S E B$ & $\boldsymbol{\beta}$ \\
\hline \multicolumn{4}{|l|}{ Outcome: Friendship quality (offline) } \\
\hline \multicolumn{4}{|l|}{ Step 1} \\
\hline Sex $($ female $=1$, male $=2)$ & -11.99 & 2.08 & $-.25 * *$ \\
\hline Grade $($ low = 1, high = 3) & -.58 & 1.51 & -.02 \\
\hline \multicolumn{4}{|l|}{ Step2 } \\
\hline Sex $($ female $=1$, male $=2)$ & -10.00 & 2.00 & $-.21 * \star$ \\
\hline Grade $($ low $=1$, high $=3)$ & -1.07 & 1.44 & -.03 \\
\hline Initial contact (online = 1 , offline $=2$ ) & 17.29 & 4.04 & $.18 * *$ \\
\hline Distance of friend's home ( $1=$ close, $5=$ far $)$ & -.12 & 1.29 & -.01 \\
\hline Frequency of contact $(1=$ low, $6=$ high $)$ & 3.97 & .68 & $.24 * *$ \\
\hline \multicolumn{4}{|l|}{ Outcome: Friendship quality (online) } \\
\hline \multicolumn{4}{|l|}{ Step } \\
\hline Sex $($ female $=1$, male $=2)$ & -5.83 & 2.68 &.$- .09 *$ \\
\hline Grade $($ low $=1$, high $=3$ ) & -.77 & 1.95 & .02 \\
\hline \multicolumn{4}{|l|}{ Step2 } \\
\hline Sex $($ female $=1$, male $=2$ ) & -5.50 & 2.45 & $-.09 *$ \\
\hline Grade $($ low $=1$, high $=3$ ) & -.20 & 1.79 & .01 \\
\hline Initial contact (online $=1$, offline $=2$ ) & 14.41 & 2.55 & $.24 * *$ \\
\hline Distance of friend's home ( $1=$ close, $5=$ far $)$ & -.25 & 1.07 & -.01 \\
\hline Frequency of contact ( $1=$ low, $6=$ high $)$ & 5.94 & .70 & $.36 * *$ \\
\hline
\end{tabular}

Note. ${ }^{*}=p<.05,{ }^{* *} p<.01$, friendship quality (offline): $R^{2}=.06$ for Step $1 ; \Delta R^{2}=.15$ for Step 2 $(p<.001)$. Friendship quality (online): $R^{2}=.01$ for Step $1 ; \Delta R^{2}=.18$ for Step $2(p<.001)$. 


\section{Discussion}

This study provides information about differences regarding the friendship quality of German preadolescents and adolescents with and without an SNS account, and potential impact factors. The results didn't reveal any significant difference regarding the quality of offline friendships between respondents with and without an SNS account (Hypothesis 1). However, there were differences in topics being discussed. The within-subjects comparisons showed that preadolescents and adolescents with SNS accounts described their offline friendships more positively than their online friendships (in line with Hypothesis 2). Regarding our third research question (Hypothesis 3) the results indicated that offline and online friendship quality of German preadolescents and adolescents with an SNS account are affected by the same descriptive factors: sex, initial offline contact, and frequency of contact.

\section{Social Network Account and Offline Friendships}

Previous findings showed that the use of ICTs in general and online media in particular may alter the quality of existing personal ties like friendships. Furthermore, the frequency of online communication within exiting ties was associated with closer friendships. Valkenburg and Peter (2007) explained their results by enhanced selfdisclosure within existing ties. Online communications make it easier to talk about topics not easily disclosed, such as feelings and worries. In our study, we used a different approach. We compared the quality of offline friendships of adolescents with and without an SNS account and defined friendship by the modality that is predominately used: offline or online. This allowed us to focus on mixed friendships which they are nowadays most common.

The results demonstrated that friendship quality and friendship strength in terms of closeness did not differ by SNS account, although SNS are the most widely used online communication form of preadolescents and adolescents. Despite the fact that there were no differences in friendship quality, the existing differences mentioned above indicated that SNS participants communicate more personal information (i.e. personal problems, secrets, girls and boys they like) with their offline friends compared to adolescents without an SNS account.

A possible interpretation could be that participation in an SNS facilitates talking about a broad scope of topics because the contacts to offline friends may be based on both face-to-face and online exchanges. An alternative explanation could be that SNS users are, in general, more socially competent in discussing personal problems with friends. Consequently, this could lead to increased exchange in offline relationships as well. Both interpretations imply the assumption that preadolescents and adolescents participating in SNSs have increased resources (exchange opportunities or personal competencies) to talk about personal problems and topics in offline friendships, which would explain the differences.

\section{Offline and Online Friendship Quality of SNS Participants}

Our findings regarding the second research question are in line with previous studies that focused on online and offline friendships. As Mesch and Talmud (2006a, 2006b, 2007) showed, friends initially met offline show higher friendship quality than do friends initially met online. In our study, initial contact was a significant predictor for online and offline friendship quality, and friendship quality was higher if the initial contact was offline. With our study, we demonstrated that despite the initial contact, the main area of communication has to be taken into account when talking about online friendship quality. As Antheunis et al. (2012) argued, the distinction between online and offline friendships by initial contact does not reflect the reality of contemporary friendship formation and maintenance. Future research has to take into account that different variables, such as initial contact, main context, and means of communication, may define friendship.

\section{Influencing Factors on Offline and Online Friendships Quality}

Although there are differences regarding perceived friendship quality, our study demonstrates that the influential factors (Hypothesis 3) are rather similar for offline and online friendships. Not surprisingly, the 
frequency of contact is associated with friendship quality in offline and online friendships. This is probably a bidirectional association because increased contact may intensify the friendship quality and, conversely, an intensive friendship may lead to increased contact frequencies. More interesting may be, however, that the kind of initial contact is important for perceived friendship quality - offline as well as online. This means that even an online friendship is more positively perceived if the friend was met offline initially. The additional online contact may be associated with an intensification of an offline friendship. As suggested by Tang (2010), the more spaces the friendship expands into (offline and online), the more intimate and rewarding it becomes. However, there is typically no perfect overlap between offline and online contacts (Subrahmanyam, Reich, Waechter, \& Espinoza, 2008), which also leaves space for experiencing new and different kinds of friendship. This is underlined by the current results because many preadolescents and adolescents described as online friends were initially, or concurrently, also met offline and vice versa.

\section{Sex and Age Differences}

Our findings showed that girls report generally higher friendship quality and stronger relationships compared to boys. These effects were shown especially for offline friendships and less strongly also for online friendships. The investigation of topics revealed that girls not just rate their friendships as closer, they also report that they share more intimate topics with their offline and online friends. This was true for both female samples (with and without SNS account) for offline and online friendships. Concerning age, the current study involved a wide grade range from fifth grade (11 years) up to tenth grade (16 years). As the description of the participants showed young preadolescents are less likely member of an SNS, but the membership proportion increases with age. However, in terms of friendship quality there were hardly any effects of adolescents' age. The only age related effects were related to more school related discussed topics at higher grades. Moreover, younger participants assessed their friendship ties as stronger than older participants.

As we tried to focus on SNSs as a specific Internet application, the question arises how the results are affected by different kinds of applications. Although most applications, such as instant messaging, chats, and SNSs, may provide similar functionalities, they may differ in their use and integration in adolescents' lives. For subsequent research, we therefore suggest paying more attention to the specific Internet applications used by adolescents. This would allow for the identification of effects of specific applications and general effects of ICT on adolescent's behaviour. This becomes even more important if the development of Internet applications and ICT during the last 10 years is reviewed. The rapid development in this area supports the expectation that new applications will be invented for use by adolescents. This can, for example, already be seen by looking at the smartphone application WhatsApp, which focuses on instant messaging in private group spaces. This application shows some similarities to applications such as SNSs, but provides new opportunities for adolescents and their friendship formation.

\section{Limitations}

Although the study showed that friendship quality of adolescents may differ in offline and online contexts, there are several limitations which have to be taken into account when discussing our findings. First, the data presented are based on a cross-sectional study, which precludes causal interpretations. Consequently, longitudinal studies which could accompany preadolescents and adolescents during their development of new friendships offline as well as online are needed. Secondly, our definition of friendship is not comparable to the typical classification of offline and online friendships, which are initially offline or online met. Therefore, our results focus on mixed friendships as defined by Atheunis et al. (2012). Thirdly, we focused only on adolescents with and without an SNS account. Although most German adolescents are part of SNS this does not mean that they do not communicate by other social media. Other social media like i.e. the mentioned smartphone application WhatsApp provide additionally opportunities for adolescents' friendship formation. Furthermore, characteristics of the society (e. g. school system, wealth) could alter the results. And finally, this study focused only on some descriptive influencing factors on offline and online friendship quality. Other known influencing factors, like personality traits (i.e. extraversion), parents' relationship quality, or aspects of children's-self have not been taken into account. 
This allows room for prospective studies with a more comprehensive study design investigating adolescents' friendship quality, in different countries and across different social media.

\section{Implications}

Despite the limitations, this study also adds some useful findings for current research. Although there are hardly any differences between adolescents participating and not participating in SNS with regard to friendship quality, the contents of the discussed topics differed. Therefore, the question arises how specific social media may alter the content of existing friendships.

The comparison of offline and online friendships based on friends predominately met online or offline gave further inside in how offline and online friendship may be perceived and how they differ in dependency of specific social media. As several previous studies showed, nowadays offline peer interactions are much more related also to online contexts. The venues (offline or online) where they are predominately maintained may have a divergent meaning for their friendship quality. Online communication may expand existing offline ties in terms of self-disclosure but the current findings show that the offline contact sets the basis for increased selfdisclosure. This becomes even more central when looking at the differences between offline and online friendships for discussed personal topics. In our study, the participants shared more often personal problems and secrets with predominately offline friends compared to predominately online friends. And finally, this study showed that although predominately offline and online friendship differ in their quality, the main influencing factors for both kinds of friendship are sex, meeting the friend initially offline and the frequency of contact.

\section{References}

Antheunis, M. L., Valkenburg, P. M., \& Peter, J. (2012). The quality of online, offline, and mixed-mode friendships among users of a social networking site. Cyberpsychology: Journal of Psychosocial Research on Cyberspace, 6(3), article 6. http://dx.doi.org/10.5817/CP2012-3-6

Baiocco R., Laghi F., Schneider B. H., Dalessio M., Amichai-Hamburger Y., Coplan R. J., ... Flament M. (2011). Daily patterns of communication and contact between Italian early adolescents and their friends. Cyberpsychology, Behavior, and Social Networking, 14, 467-471. http://dx.doi.org/10.1089/cyber.2010.0208

Behling, O., \& Law, K. S. (2000). Translating questionnaires and other research instruments: Problems and solutions. Thousand Oaks, CA: Sage Publications.

Berndt, T. J. (2002). Friendship quality and social development. Current Directions in Psychological Science, 11, 710. http://dx.doi.org/10.1111/1467-8721.00157

Bigelow, B. J., \& LaGaipa, J. J. (1980). The development of friendship values and choice. In H. C. Foot, A. J. Chapman, \& J. R. Smith (Eds.), Friendship and social relations in children (pp. 15-44). New York: John Wiley.

Bryant, J. A., Sanders-Jackson A., \& Smallwood A. M. K. (2006) IMing, text messaging and adolescent social networks. Journal of Computer-Mediated Communication, 11, 577-592.

Bukowski, W. M., Hoza, B., \& Boivin, M. (1994). Measuring friendship quality during pre- and early adolescence: The development and psychometric properties of the Friendship Qualities Scale. Journal of Social and Personal Relationships, 11, 471-484. http://dx.doi.org/10.1177/0265407594113011

Desjarlais, M., \& Willoughby, T. (2010). A longitudinal study of the relation between adolescent boys' and girls' computer use with friends and friendship quality: Support for the social compensation or the rich-get-richer hypothesis? Computers in Human Behavior, 26, 96-905. http://dx.doi.org/10.1016/j.chb.2010.02.004

EFS Survey. (Version 10.1). [Computer Software]. Koeln: QuestBack GmbH. 
Gross, E. F. (2004). Adolescent Internet use: What we expect, what teens report. Journal of Applied Developmental Psychology, 25, 633-649. http://dx.doi.org/10.1016/j.appdev.2004.09.005

Hartup, W. W., \& Stevens, N. (1997). Friendships and adaptation in the life course. Psychological Bulletin, 121, 355370.

Hartup, W. W., \& Stevens, N. (1999). Friendships and adaptation across the life span. Current Directions in Psychological Science, 8, 76-79. http://dx.doi.org/10.1111/1467-8721.00018

Laghi F., Vitoroulis I., Schneider B. H., Coplan R. J., Baiocco R., Amichai-Hamburger Y., ... Flament M. (2013). Knowing when not to use the internet: Shyness and adolescents' on-line and off-line interactions with friends. Computers in Human Behavior, 29, 51-57. http://dx.doi.org/10.1016/j.chb.2012.07.015

Lenhart, A., Madden, M., \& Hitlin, P. (2005). Teens and technology: Youth are leading the transition to a fully wired and mobile nation. Washington DC: Pew Internet \& American Life Project. Retrieved from http://www.pewinternet.org/files/old-media/Files/Reports/2005/PIP_Teens_Tech_July2005web.pdf.pdf

McKenna, K., Green, A. S., \& Gleason, M. E. G. (2002). Relationship formation on the Internet: What is the big attraction? Journal of Social Issues, 58, 1, 9-31. http://dx.doi.org/10.1111/1540-4560.00246

Mendelson, M. J., \& Aboud, F. (1999). Measuring friendship quality in late adolescents and young adults: McGill friendship questionnaires. Canadian Journal of Behavioural Science, 31, 130-132.

http://dx.doi.org/10.1037/h0087080

Mendelson, M. J., \& Aboud, F. (2012). McGill Friendship Questionnaire \& Friendship Functions (MFQ-FF). Measurement instrument database for the social science. http://dx.doi.org/10.13072/midss.170

Mesch, G. S. (2001). Social relationships and Internet use among adolescents in Israel. Social Science Quarterly, 82, 329-340. http://dx.doi.org/10.1111/0038-4941.00026

Mesch, G. S., \& Talmud, I. (2006a). The quality of online and offline relationships: The role of multiplexity and duration of social relationships. Information Society, 22, 137-148. http://dx.doi.org/10.1080/01972240600677805

Mesch, G. S., \& Talmud, I. (2006b). Online friendship formation, communication channels, and social closeness. International Journal of Internet Science, 1, 29-44.

Mesch, G. S., \& Talmud, I. (2007). Similarity and the quality of online and offline social relationships among adolescents in Israel. Journal of Research on Adolescence, 17, 455-465. http://dx.doi.org/ 10.1111/j.15327795.2007.00529.x

Mesch, G. S., \& Talmud, I. (2010). Wired youth: The social world of adolescence in the information age. London: Routledge.

MFS (Medienpädagogischer Forschungsverbund Südwest). (2014). Jugend, Information, (Multi)Media (JIM2013). Basisstudie zum Medienumgang 12- bis 19-Jähriger in Deutschland [Survey of 12 to 19 years old adolescents' media use in Germany]. Retrieved from http://www.mpfs.de/fileadmin/JIM-pdf14/JIMStudie2014.pdf

Newcombe, A.F., \& Bagwell, C.L. (1995). Children's friendship relations: A meta-analytic review. Psychological Bulletin, 117, 306-347. http://dx.doi.org/10.1037/0033-2909.117.2.306

Parker, J. G., Rubin, K. H., Erath, S. A., Wojslawowicz, J. C., \& Buskirk, A. A. (2006). Peer relationships, child development, and adjustment: A developmental psychopathology perspective. In D. Cicchetti \& D. J. Cohen (Eds.), Theory and method: Vol. 1. Developmental psychopathology (2nd ed., pp. 419-493). Hoboken, NJ: John Wiley \& Sons. 
Punamäki, R.-L., Wallenius, M. Hölttö, H., Nygård, C-H., \& Rimpelä, A. (2009). The associations between information and communication technology (ICT) and peer and parent relations in early adolescence. International Journal of Behavioral Development, 33, 556-564.

Reich, S. M., Subrahmanyam, K., \& Espinoza, G. (2012). Friending, IMing, and hanging out face-to-face: Overlap in adolescents' online and offline social networks. Developmental Psychology, 48, 356-368.

http://dx.doi.org/10.1037/a0026980

Rideout, V. J., Foehr, U. G., \& Roberts, D. F. (2010). Generation M2: Media in the lives of 8- to 18-year-olds. Menlo Park, CA: The Henry J. Kaiser Family Foundation.

Schouten, A. P., Valkenburg, P. M., \& Peter, J. (2009). An experimental test of processes underlying self-disclosure in computer-mediated communication. Cyberpsychology: Journal of Psychosocial Research on Cyberspace, 3(2), article 3. Retrieved from http://cyberpsychology.eu/view.php?cisloclanku=2009111601\&article=3

Selman, R. L. (1981). The child as friendship philosopher. In S. R. Asher \& J. M. Gottman (Eds.), The development of children's friendship (pp. 242-272). New York: Cambridge University Press.

Statistisches Bundesamt. (2013). Ausländische Schüler/innen nach Schularten und Anteilen. Retrieved from https://www.destatis.de/..../AllgemeinBildendeBeruflicheAuslaendischeSchueler.html

Subrahmanyam, K., Reich, S. M., Waechter, N., \& Espinoza, G. (2008). Online and offline social networks: Use of social networking sites by emerging adults. Journal of Applied Developmental Psychology, 29, 420-433.

http://dx.doi.org/10.1016/j.appdev.2008.07.003

Tang, L. (2010). Development of online friendship in different social spaces. Information, Communication and Society, 13, 615-633. http://dx.doi.org/10.1080/13691180902998639

Valkenburg, P. M., \& Peter, J. (2007). Preadolescents' and adolescents' online communication and their closeness to friends. Developmental Psychology, 43, 267-277. http://dx.doi.org/10.1037/0012-1649.43.2.267

Valkenburg, P. M., \& Peter, J. (2009). Social consequences of the Internet for adolescents: A decade of research. Current Directions in Psychological Science, 18, 1-5. http://dx.doi.org/10.1111/j.1467-8721.2009.01595.x

Valkenburg, P. M. Peter, J., \& Schouten, A. P. (2006). Friend networking sites and their relationship to adolescents' well-being and social self-esteem. CyberPsychology \& Behavior, 9, 584-590.

http://dx.doi.org/10.1089/cpb.2006.9.584

Valkenburg, P. M., Sumter, S. R., \& Peter, J. (2011). Gender differences in online and offline self-disclosure in preadolescence and adolescence. British Journal of Developmental Psychology, 29, 253-269.

http://dx.doi.org/10.1348/2044-835X.002001

Williams, A. L., Merten, M. J. (2008). A review of online social networking profiles by adolescents: Implications for future research and intervention. Adolescence, 43, 253-274.

\section{Correspondence to:}

Dr. Michael Glüer

Bielefeld University

Department of Psychology

P.O. Box 100131

33501 Bielefeld

Germany

Email: michael.glueer(at)uni-bielefeld.de 


\begin{abstract}
About authors
Dr. Michael Glüer is Assistant Professor of Developmental Psychology at the University of Bielefeld, Germany. His research interests are related to new media in childhood, relationship quality in early childhood and early childhood education.

Dr. Arnold Lohaus is Professor of Developmental Psychology and Developmental Psychopathology at the University of Bielefeld, Germany. His research interests are related to health promotion in children and adolescents (development of health and coping behaviour, stress management in children and adolescents).
\end{abstract}

